\title{
Thyroperoxidase Measurement
}

National Cancer Institute

\section{Source}

National Cancer Institute. Thyroperoxidase Measurement. NCI Thesaurus. Code C96639.

The determination of the amount of thyroperoxidase present in a sample. 